\title{
Growth Hormone (GH) Status and Body Composition in Normal Ageing and in Elderly Adults with GH Deficiency
}

\author{
Andrew A. Toogood \\ University of Birmingham, Queen Elizabeth Hospital, Birmingham, UK
}

\author{
Key Words \\ Growth hormone - Growth hormone deficiency $\cdot$ Body \\ composition · Elderly adults · Ageing
}

\begin{abstract}
Similarities have been observed between the changes associated with ageing and the symptoms of growth hormone $(\mathrm{GH})$ deficiency. Changes such as increased fat mass and decreased muscle mass occur both in $\mathrm{GH}$-deficient patients and in otherwise healthy elderly individuals. Moreover, ageing is associated with decreasing $\mathrm{GH}$ and insulin-like growth factor I (IGF-I) levels. It has been suggested, therefore, that hypothalamic-pituitary disease leading to $\mathrm{GH}$ deficiency (GHD) in elderly patients would have less impact than in younger adults. Studies suggest that healthy elderly individuals have normal pituitary reserves of $\mathrm{GH}$, but that spontaneous $\mathrm{GH}$ secretion falls by around $14 \%$ per decade of adult life, leading to a state of functional GH insufficiency. Despite this, elderly patients with GHD experience reductions in $\mathrm{GH}$ secretion and IGF-I levels, compared with controls, which are of similar magnitude to those seen in younger $\mathrm{GH}$-deficient adults. The metabolic changes associated with GHD are also seen in elderly patients compared with healthy elderly controls. Fat mass, particularly in
\end{abstract}

the abdominal region, is significantly increased, with a strong correlation between fat mass and body mass index. Markers of bone formation and resorption are significantly reduced in the $\mathrm{GH}$-deficient patients. Elderly adults who have hypothalamic-pituitary disease have a degree of GHD that can be distinguished from the decline in GH and IGF-I levels that is seen with normal ageing. GHD in elderly patients leads to significant changes in body composition and bone. Thus, these patients are likely to benefit from $\mathrm{GH}$ replacement therapy.

Copyright @ 2003 S. Karger AG, Basel

\section{Introduction}

Severe growth hormone ( $\mathrm{GH}$ ) deficiency in adults with hypothalamic-pituitary disease is characterized by adverse changes in body composition (increased fat mass and decreased lean mass), osteopaenia, reduced exercise tolerance, decreased strength and an impaired quality of life [1]. In addition, patients with multiple anterior pituitary hormone deficits, receiving 'conventional' replacement therapy but not $\mathrm{GH}$ replacement therapy, exhibit an adverse cardiovascular risk profile [2] and have an almost twofold increase in mortality [3].

\begin{tabular}{ll}
\hline KARGER & ( ) 2003 S. Karger AG, Basel \\
0301-0163/03/0607-0105\$19.50/0 \\
$\begin{array}{l}\text { Fax +4161306 12 34 } \\
\begin{array}{l}\text { E-Mail karger@karger.ch } \\
\text { www.karger.com }\end{array}\end{array}$ & $\begin{array}{l}\text { Accessible online at: } \\
\text { www.karger.com/hre }\end{array}$
\end{tabular}

Dr. A.A. Toogood

Division of Medical Sciences, University of Birmingham

Queen Elizabeth Hospital

Edgbaston, Birmingham B15 2TH (UK)

Tel. +44 121472 1311, ext. 3923, Fax +44 121627 2384, E-Mail a.a.Toogood@bham.ac.uk 


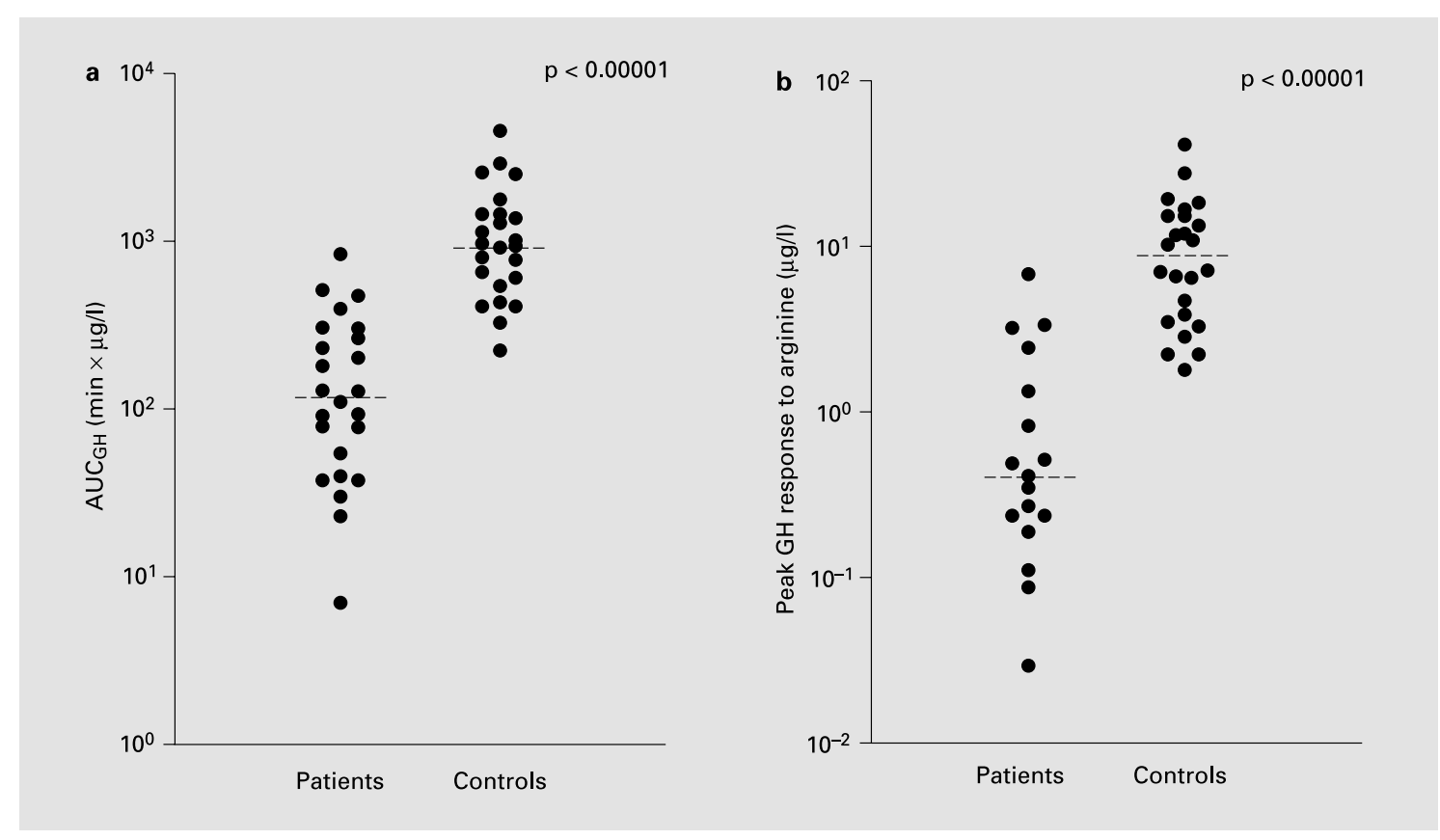

Fig. 1. GH secretion in 24 patients with hypothalamic-pituitary disease and 24 control participants. a Area under the curve of the 24-hour GH profile (20-min sampling) and $\mathbf{b}$ peak GH response to arginine. Serum concentrations of $\mathrm{GH}$ were measured using an ultrasensitive chemiluminescence assay (sensitivity $0.002 \mu \mathrm{g} / \mathrm{l}$ ). Median values are indicated by horizontal bars. Reproduced, with permission, from Toogood et al. [10]: ${ }^{\odot}$ Blackwell.

Similar changes occur as a result of ageing. For example, during adult life, a man will, on average, lose $12 \mathrm{~kg}$ of lean tissue (5 $\mathrm{kg}$ in women) and gain $12 \mathrm{~kg}$ of fat mass (15 kg in women) [4]. In addition, bone mass is reduced and there is a deterioration in markers of cardiovascular risk associated with increased mortality. These changes occur against a background of declining GH secretion and serum levels of insulin-like growth factor I (IGF-I). The similarity between the pathophysiology of ageing and $\mathrm{GH}$ deficiency (GHD) has been reported, and it has also been suggested that GH may be used to improve strength, exercise capacity and functional ability in older individuals, reversing some of the effects of ageing [5]. On a less realistic note, it has been suggested that GH treatment may restore youth and prolong life, but there are no data to support this outcome [6].

\section{GH Status in Healthy Elderly Individuals}

It is often stated that old age is a GH-deficient state. The GH Research Society consensus statement on the diagnosis of GHD, however, states that in adults, hypothalamic-pituitary disease must be present before the diagnosis of GHD can be considered and that the peak GH response during an insulin tolerance test (ITT) should be less than $3 \mu \mathrm{g} / 1$ [7]. The $\mathrm{GH}$ response during an ITT has been reported to fall with increasing age in one study [8], but was unaffected in another [9]. The GH response to arginine alone [10], arginine + GH-releasing hormone (GHRH) [11] or GHRH + GH-releasing peptide 6 [12] is sustained across the adult lifespan, suggesting that the releasable reserve of $\mathrm{GH}$ in the pituitary gland is not affected by age. Spontaneous GH secretion falls by an estimated $14 \%$ per decade of adult life [13], an alteration caused by changes in hypothalamic release of GHRH and somatostatin [14]. These data suggest that ageing results in a state of functional GH insufficiency.

\section{GH Status in Elderly Patients with Hypothalamic-Pituitary Disease}

If the hyposomatotropism associated with an increase in age was severe enough to be labelled as GHD, one would not expect hypothalamic-pituitary disease to have a significant impact on spontaneous GH secretion in adults over 60 years of age. To address this question, 


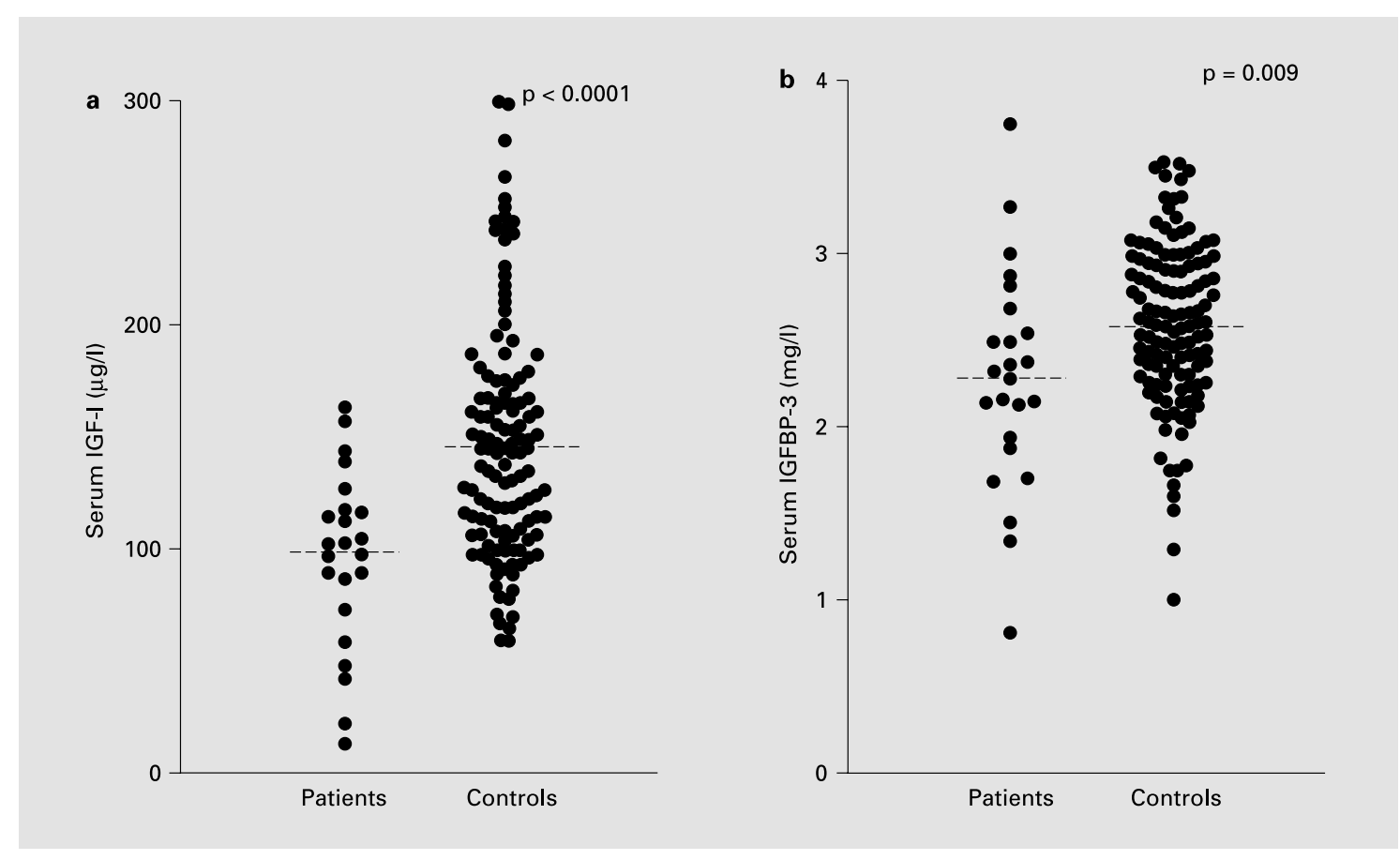

Fig. 2. Serum concentrations of IGF-I (a) and IGFBP-3 (b) in 24 patients with hypothalamic-pituitary disease compared with data from 125 control individuals aged over 60 years. Median values are indicated by horizontal bars. Adapted, with permission, from Toogood et al. [10]: ${ }^{\circ}$ Blackwell.

spontaneous and stimulated $\mathrm{GH}$ secretion was studied in 24 patients with hypothalamic-pituitary disease and 24 controls aged over 60 years. The groups did not differ significantly in terms of body mass index (BMI), but the patients with hypothalamic-pituitary disease were slightly younger than the controls (66.0 years [range, 61.0-85.7 years] vs. 70.6 years [60.8-87.5 years], respectively; $\mathrm{p}=$ 0.04). Each participant underwent a 24-hour GH profile, when a sample was taken every $20 \mathrm{~min}$, and an arginine stimulation test performed immediately after the profile. Blood was also taken for an estimation of serum concentrations of IGF-I and IGF-binding protein 3 (IGFBP-3) following an overnight fast.

With the use of a standard GH immunoradiometric analysis (sensitivity, $0.4 \mu \mathrm{g} / \mathrm{l}$ ), it was shown that 16 of the 24 patients had no detectable release of GH. In contrast, all of the control participants had detectable GH secretion at some point during the 24 -hour profile [15]. When reevaluated using an ultrasensitive chemiluminescence assay (sensitivity, $0.002 \mu \mathrm{g} / \mathrm{l}$ ), GH was measurable in all of the samples obtained during the 24-hour profiles from the controls and the patients [16]. The area under the curve of the $\mathrm{GH}$ profile $\left(\mathrm{AUC}_{\mathrm{GH}}\right)$ was significantly lower in the patients with hypothalamic-pituitary disease than in the control participants, $119.3 \mu \mathrm{g} / 1 \cdot \min$ (range, $7.3-843.6 \mu \mathrm{g} /$ $1 \cdot \mathrm{min}$ ) compared with $968.5 \mu \mathrm{g} / \mathrm{l} \cdot \mathrm{min}$ (range, 227.2$4,625.0 \mu \mathrm{g} / 1 \cdot \min )(\mathrm{p}<0.00001)$ (fig. 1). Thus, GH secretion in the patients with hypothalamic-pituitary disease was only $12 \%$ of that observed in the controls, a reduction similar in size to that observed in younger adults with hypothalamic-pituitary disease [17]. A similar reduction was observed in the peak GH response to arginine stimulation (fig. 1) [10]. Serum levels of IGF-I and IGFBP-3 were significantly lower in the patients than in the controls $(102 \mu \mathrm{g} / 1$ [range, $14-162 \mu \mathrm{g} / 1]$ vs. $142 \mu \mathrm{g} / 1$ [59-298 $\mu \mathrm{g} / \mathrm{l}]$ $[\mathrm{p}<0.0001]$ and $2.29 \mathrm{mg} / 1[0.81-3.75 \mathrm{mg} / \mathrm{l}]$ vs. $2.59 \mathrm{mg} / \mathrm{l}$ $[1.00-3.52 \mathrm{mg} / \mathrm{l}][\mathrm{p}=0.009]$, respectively), but there was a significant degree of overlap between the two groups (fig. 2).

\section{The Impact of GHD on Body Composition and Bone in Adults over 60 Years of Age}

Hypothalamic-pituitary disease in adults over 60 years of age causes a reduction in GH secretion beyond that associated with an increase of age. The magnitude of the decrease is similar to the decrease observed in younger 
adults with pituitary disease [17] and is severe enough to cause a reduction in serum levels of IGF-I and IGFBP-3. To determine whether GHD in elderly individuals had a significant impact upon body composition and bone, 21 patients and 24 controls of similar age, height, weight and BMI underwent dual-energy X-ray absorptiometry scanning of the hip, spine and total body. In addition, a 24hour urine collection was performed and serum was analysed for an estimation of deoxypyridinoline excretion and osteocalcin, respectively.

\section{Body Composition}

Fat mass was significantly increased in the patients with hypothalamic-pituitary disease $(27.8 \mathrm{~kg}$ [range, $19.2-$ $50.2 \mathrm{~kg}])$, compared with the control group (21.2 kg [8.8$49.2 \mathrm{~kg}$ ]; $\mathrm{p}<0.005)$. Estimation of regional fat mass showed that these patients had a greater fat mass in the trunk, in the arms and in the legs than the control participants (table 1). There was a strong correlation between total fat mass and BMI in the control participants $(r=0.80 ; p<0.0001)$, but this relationship was not seen in the patients $(r=0.23)$, suggesting that body composition was abnormal in these individuals. The waist:hip ratio was higher in the patients with hypothalamic-pituitary disease $(0.93$ [0.70-1.17]) than in the control participants $(0.89$ [0.69-1.02]; $\mathrm{p}<0.05)$, suggesting that the degree of central obesity was greater in the patients. There was a significant negative correlation between total fat mass and $\mathrm{GH}$ secretion $\left(\mathrm{AUC}_{\mathrm{GH}}\right)$ in the control participants $(r=-0.542 ; p=0.006)$, but this relationship was not evident in the patients with hypothalamicpituitary disease $(r=-0.127 ; p=0.58)$.

In contrast to younger patients with GHD, total fatfree mass was not significantly different in elderly patients with GHD compared with their healthy peers $(50.87 \mathrm{~kg}$ [range, $26.96-69.18 \mathrm{~kg}$ ] vs. $51.55 \mathrm{~kg}$ [32.35-60.53 kg]; $\mathrm{p}=$ 0.8 ). The fat-free mass in the arms, legs and trunk were not significantly different between the two groups (table 1) [18].

\section{Bone}

Markers of bone formation and resorption were significantly reduced in the patients with hypothalamic-pituitary disease compared with the controls. The median serum concentration of osteocalcin was $11.5 \mathrm{ng} / \mathrm{ml}$ (range, $3.6-23.0 \mathrm{ng} / \mathrm{ml})$ versus $15.1 \mathrm{ng} / \mathrm{ml}(0.7-40.5 \mathrm{ng} / \mathrm{ml} ; \mathrm{p}=$ $0.019)$, and the deoxypyridinoline:creatinine ratio was $3.5 \mu \mathrm{mol} / \mathrm{mol}(0.8-8.3 \mu \mathrm{mol} / \mathrm{mol})$ versus $4.9 \mu \mathrm{mol} / \mathrm{mol}$ $(3.0-9.7 \mu \mathrm{mol} / \mathrm{mol} ; \mathrm{p}=0.038)$, in the patients and controls, respectively. In the control group, there was a significant correlation between serum levels of osteocalcin and $\mathrm{AUC}_{\mathrm{GH}}(\mathrm{r}=0.43 ; \mathrm{p}=0.039)$ and urinary deoxypyridinoline cross-links and age $(r=0.64 ; p=0.002)$. These rela-
Table 1. Fat and lean mass measured in elderly patients with hypothalamic-pituitary disease and elderly controls

\begin{tabular}{lccl}
\hline Mass, kg & Patients $(\mathrm{n}=21)$ & Controls $(\mathrm{n}=24)$ & $\mathrm{p}$ \\
\hline Total fat & $27.5(19.2-50.2)$ & $21.2(8.8-49.2)$ & 0.0047 \\
Total lean & $50.9(27.0-69.2)$ & $51.6(32.4-60.5)$ & 0.8 \\
Arms, fat & $3.3(2.0-8.3)$ & $2.4(0.8-7.1)$ & 0.033 \\
Legs, fat & $7.3(4.2-16.4)$ & $5.6(2.4-17.1)$ & 0.021 \\
Trunk, fat & $15.7(10.0-24.1)$ & $12.4(5.1-23.2)$ & 0.009 \\
Arms, lean & $6.7(2.8-8.6)$ & $6.5(3.5-8.1)$ & 0.9 \\
Legs, lean & $16.2(8.8-22.5)$ & $17.1(10.6-21.0)$ & 0.4 \\
Trunk, lean & $24.4(12.5-35.2)$ & $24.8(15.3-29.9)$ & 0.96 \\
\hline
\end{tabular}

Values are expressed as median (range).

\begin{tabular}{llll}
\hline & Patients $(\mathrm{n}=21)$ & Controls $(\mathrm{n}=24)$ & $\mathrm{p}$ \\
\hline Vertebrae L2-L4 & $0.80(-2.83$ to 2.95$)$ & $1.10(-2.87$ to 2.64$)$ & 0.68 \\
Femoral neck & $0.27(-1.48$ to 3.43$)$ & $0.25(-2.29$ to 3.26$)$ & 0.89 \\
Femoral trochanter & $0.46(-2.14$ to 3.37$)$ & $0.50(-2.4$ to 3.8$)$ & 0.98 \\
Ward's triangle & $0.10(-1.58$ to 3.94$)$ & $0.47(-2.45$ to 3.31$)$ & 0.96 \\
\hline
\end{tabular}

Values are expressed as median (range).
Table 2. Age-specific standard deviation scores at each site measured in elderly patients with hypothalamic-pituitary disease and elderly controls
Toogood 

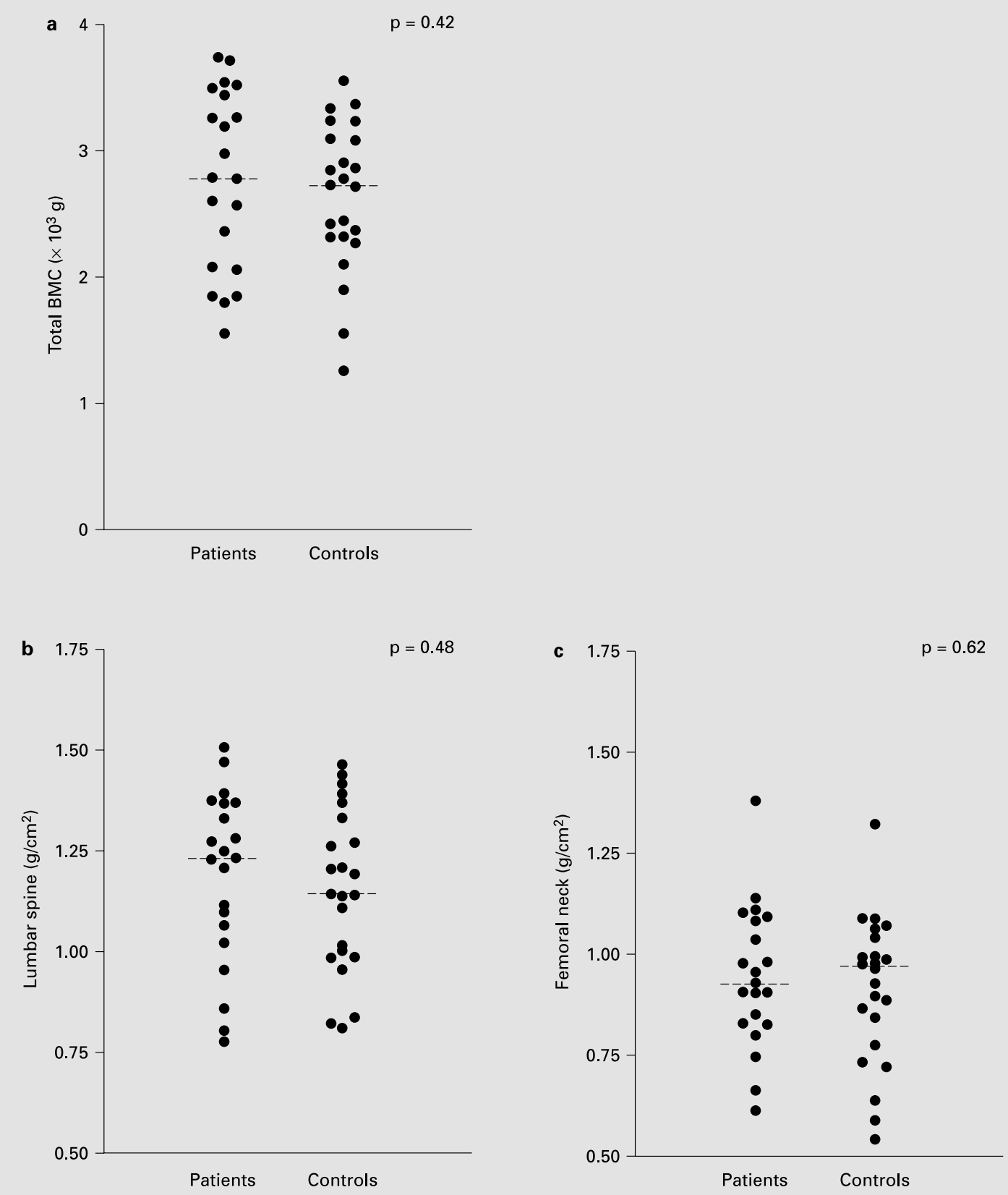

Fig. 3. Measurement of bone mineral in 21 patients with hypothalamic-pituitary disease and 23 control individuals. a Total bone mineral content (BMC), and bone mineral density measured at $\mathbf{b}$ the lumbar spine and $\mathbf{c}$ the hip. Median values are indicated by horizontal bars. Adapted, with permission, from Toogood et al. [19]: ${ }^{\odot}$ The Endocrine Society.

tionships were not seen in the patients with hypothalamic-pituitary disease. Despite this reduction in bone turnover, total body bone mineral content and bone mineral density at the hip and spine were almost identical in both groups (fig. 3, table 2) [19].

GH and Body Composition in Ageing and Elderly GH-Deficient Adults

\section{Discussion}

Adults over the age of 60 years who have hypothalamic-pituitary disease have a degree of GHD that can be distinguished from the hyposomatotropism of ageing; spon-

Horm Res 2003;60(suppl 1):105-11

109 
taneous secretion of $\mathrm{GH}$ is only $12 \%$ of that observed in healthy controls. This degree of GHD is significant enough to impact on serum markers, body composition and bone. The magnitude of the changes that occur, however, is attenuated compared with those changes observed in younger patients with a similar deficit in $\mathrm{GH}$ secretion.

A considerable degree of interest surrounds the use of $\mathrm{GH}$ as an anti-ageing compound. There are some 'special clinics' in many countries that offer $\mathrm{GH}$ treatment to paying customers on the grounds that the process of ageing will be reversed. Some researchers also claim that $\mathrm{GH}$ may extend the human life span. The short-to-mediumterm effects of GH treatment, however, as shown through well-designed, randomized, controlled studies are less impressive. Improvements in body composition occur, but improvements in physical function are difficult to demonstrate [20]. Furthermore, many authors report a high incidence of adverse effects including gynaecomastia, carpal tunnel syndrome, peripheral oedema and impaired glucose tolerance. The lack of efficacy demonstrated and the high incidence of side effects reported during $\mathrm{GH}$ treatment suggest that older adults are not truly GH deficient, a supposition confirmed by the studies discussed in this review. In addition, the observation that the effects of GHD in older adults are attenuated suggests that changes in body composition, muscle mass and strength are not driven solely by the observed changes in $\mathrm{GH}$ status that occur with increasing age. Thus, GH should not be considered as an elixir of youth to be administered to all adults over the age of 60 years. Research efforts should, instead, focus on identifying groups of patients in whom the risk of adverse effects is outweighed by the benefits achieved from $\mathrm{GH}$ treatment.

Patients over the age of 60 years who have hypothalamic-pituitary disease, on the other hand, do suffer from the effects of GHD, which suggests that these patients would benefit from GH replacement therapy. Li Voon Chong et al., who studied the quality of life in these patients, demonstrated that patients had less energy, mobility and personal life fulfilment, and had more problems with emotional reaction, social isolation and mental fatigue. Li Voon Chong and colleagues also reported a greater impairment in some areas of social functioning, general health and mental health compared with healthy controls [21]. Although there are no data from controlled studies, $\mathrm{GH}$ replacement therapy appears to be beneficial to adults over the age of 60 years with organic GHD. In an open, dose-finding study, serum IGF-I increased, fat mass fell, lean mass increased and there was a significant improvement in quality of life determined using the Adult GHD Assessment (AGHDA) questionnaire [22]. Data from KIMS (Pharmacia International Metabolic Database) indicate that 6 months of GH replacement therapy in adults over 60 years of age resulted in a reduction of waist circumference, waist:hip ratio, diastolic blood pressure, total and low-density lipoprotein cholesterol, and an improvement in quality of life as determined by the AGHDA score [23]. Thus, there is a strong case for a welldesigned, placebo-controlled study to confirm these effects and to determine other benefits that may strengthen the case for treating patients with organic GHD, for example improvements in functional parameters such as exercise capacity.

In conclusion, it is clear that $\mathrm{GH}$ continues to have a role in metabolism and bone physiology throughout the human life span and that specific patient groups may benefit from treatment with $\mathrm{GH}$. More work is required to define the effects of GHD in patients over the age of 60 years and to identify other patients who do not have pituitary disease but could potentially benefit from the anabolic effects of $\mathrm{GH}$.

\section{References}

1 Drake WM, Howell SJ, Monson JP, Shalet SM: Optimizing GH therapy in adults and children. Endocr Rev 2001;22:425-450.

2 Beshyah SA, Johnston DG: Cardiovascular disease and risk factors in adults with hypopituitarism. Clin Endocrinol 1999;50:1-15.

3 Tomlinson JW, Holden N, Hills RK, Wheatley K, Clayton RN, Bates AS, Sheppard MC, Stewart PM: Association between premature mortality and hypopituitarism. West Midlands Prospective Hypopituitary Study Group. Lancet 2001;357:425-431.
4 Forbes GB, Reina JC: Adult lean body mass declines with age: some longitudinal observations. Metabolism 1970;19:653-663.

5 Marcus R, Hoffman AR: Growth hormone as therapy for older men and women. Annu Rev Pharmacol Toxicol 1998;38:45-61.

6 Klatz R, Kahn C: Grow young with HGH, ed 1. New York, Perennial (Harper Collins), 1998.
7 Consensus guidelines for the diagnosis and treatment of adults with growth hormone deficiency: Summary statement of the Growth Hormone Research Society workshop on Adult Growth Hormone Deficiency. J Clin Endocrinol Metab 1998;83:379-381.

8 Muggeo M, Fedele D, Tiengo A, Moliari M, Crepaldi G: Human growth hormone and cortisol responses to insulin stimulation in ageing. J Gerontol 1975;30:546-551. 
9 Kalk WJ, Vinik AI, Pimstone BL, Jackson PU: Growth hormone responses to insulin hypoglycaemia in the elderly. J Gerontol 1973;28:431433.

10 Toogood AA, Jones J, O'Neill PA, Thorner MO, Shalet SM: The diagnosis of severe growth hormone deficiency in elderly patients with hypothalamic-pituitary disease. Clin Endocrinol 1998;48:569-576.

11 Ghigo E, Aimaretti G, Gianotti L, Bellone J, Arvat E, Camanni F: New approach to the diagnosis of growth hormone deficiency in adults. Eur J Endocrinol 1996;134:352-356.

12 Popovic V, Leal A, Micic D, Koppeschaar HP Torres E, Paramo C, Obradovic S, Dieguez C, Casanueva FF: GH-releasing hormone and $\mathrm{GH}$-releasing peptide- 6 for diagnostic testing in GH-deficient adults. 2000;356:1137-1142.

13 Iranmanesh A, Lizarralde G, Veldhuis JD: Age and relative obesity are specific negative determinants of the frequency and amplitude of growth hormone $(\mathrm{GH})$ secretory bursts and the half-life of endogenous $\mathrm{GH}$ in healthy men. J Clin Endocrinol Metab 1991;73:1081-1088.

14 Giustina A, Veldhuis JD: Pathophysiology of the neuroregulation of growth hormone secretion in experimental animals and the human. Endocr Rev 1998;19:717-797.
15 Toogood AA, O’Neill PA, Shalet SM: Beyond the somatopause: growth hormone deficiency in adults over the age of 60 years. J Clin Endocrinol Metab 1996;81:460-465.

16 Toogood AA, Nass RM, Pezzoli SS, O’Neill PA, Thorner MO, Shalet SM: Preservation of growth hormone pulsatility despite pituitary pathology, surgery and irradiation. J Clin Endocrinol Metab 1997;82:2215-2221.

17 Reutens AT, Veldhuis JD, Hoffman DM, Leung KC, Ho KK: A highly sensitive growth hormone $(\mathrm{GH})$ enzyme-linked immunosorbent assay uncovers increased contribution of a tonic mode of $\mathrm{GH}$ secretion in adults with organic GH deficiency. J Clin Endocrinol Metab 1996;81:1591-1597.

18 Toogood AA, Adams JE, O’Neill PA, Shalet SM: Body composition in growth hormone deficient adults over the age of 60 years. Clin Endocrinol 1996;45:399-405.

19 Toogood AA, Adams JE, O'Neill PA, Shalet SM: Elderly patients with adult onset growth hormone deficiency are not osteopenic. J Clin Endocrinol Metab 1997;82:1462-1466.
20 Blackman MR, Sorkin JD, Munzer T, Bellantoni MF, Busby-Whitehead J, Stevens TE, Jayme J, O’Connor KG, Christmas C, Tobin JD, Stewart KJ, Cottrell E, St Clair C, Pabst KM, Harman SM: Growth hormone and sex steroid administration in healthy aged women and men: A randomized controlled trial. JAMA 2002;288:2282-2292.

21 Li Voon Chong JS, Benbow S, Foy P, Wallymahmed ME, Wile D, MacFarlane I: Elderly people with hypothalamic-pituitary disease and growth hormone deficiency: lipid profiles, body composition and quality of life compared with control subjects. Clin Endocrinol (Oxf) 2000;53:551-559.

22 Toogood A, Shalet S: Growth hormone replacement therapy in the elderly with hypothalamicpituitary disease: A dose finding study. J Clin Endocrinol Metab 1999;84:131-136.

23 Monson JP, Abs R, Bengtsson BA, Bennmarker H, Feldt-Rasmussen U, Hernberg-Stahl E, Thoren M, Westberg B, Wilton P, Wuster C: Growth hormone deficiency and replacement in elderly hypopituitary adults. KIMS Study Group and the KIMS International Board. Pharmacia and Upjohn International Metabolic Database. Clin Endocrinol (Oxf) 2000;53: 281-289. 